FACULdADE DE CIÊNCIAS ECONÔ MICAS DA UFRGS

MACROECONOMIA DO BRASIL PÓS-1994 LUIZ CARLOS BRESSER-PEREIRA

DESENVOLVIMENTO ECONOMMICO, PREFERÊNCIA PELA LIQUIDEZ E ACESSO BANCÁRIO: UM ESTUDO DE CASO DAS MESORREGIÓES DE MINAS GERAIS

MARCO CROCCO, CLAUDIO BARRA DE CASTRO, ANDERSON CAVALCANTE E VANESSA DA COSTA VAL

FRIEDMAN E O MONETARISMO: A VELHA TEORIA QUANTITATIVA DA MOEDA E A MODERNA ESCOLA MONETARISTA

GENTIL CORAZZAE RODRIGO L. KREMER

BOLLHAS RACIONAIS, CICLO DE PREÇOS DE ATIVOS E RACIONALIDADE LIMITADA: UMA AVALIACAOO CRITICA DOS MODELOS NEOCLÁSSICOS DE BOLHAS ESPECULATIVAS JOSÉ LUIS OREIRO

VULNERABILITY INDICATORS OF THE TWIN CRISES: THE EAST ASIAN EPISODE

TITO BELCHIOR SILVA MOREIRA

IMPACTOS POTENCIAIS DA NEGOCIAÇÃO DA ALCA SOBRE OS INVESTIMENTOS EXTERNOS EM SERVIÇOS PROFISSIONAIS NO BRASIL

MICHEL ALEXANDRE, OTAVIANO CANUTO E GILBERTO TADEU LIMA

TEORIA MARXISTA DO VALOR: UMA INTRODUÇẢO ALFREDO SAAD FILHO

UM ESTUDO EMPIRICO DOS CICLOS POLITICO. ECONOOMICOS NO BRASIL

ATHOS PRATES DA SILVEIRA PREUSSLER E MARCELO SAVINO PORTUGAL

RELENDO CHANDLER, WILLIAMSON E NORTH PARA ENTENDER O PROCESSO DE FORMACĀO DAS ESTRADAS DE FERRO NO BRASIL

JEFFERSON ANDRONIO RAMUNDO STADUTO

WEIMAR FREIRE DA ROCHA IR. E CLAIITON ATAIDES DE FREITAS

MATRIZ DE INSUMO-PRODUTO PARA A ECONOMIA TURISTICA BRASILEIRA: CONSTRUCCÃO E ANÁLISE DAS RELAÇÓES INTERSETORIAIS

FRANCISCO CASIMIRO FILHO E JOAQUIM JOSÉ MARTINS GUILHOTO

SEÇĀO ESPECIAL: AVALIAÇŌES INICIAIS DA POLITTICA ECONÓMICA DO GOVERNO LULA

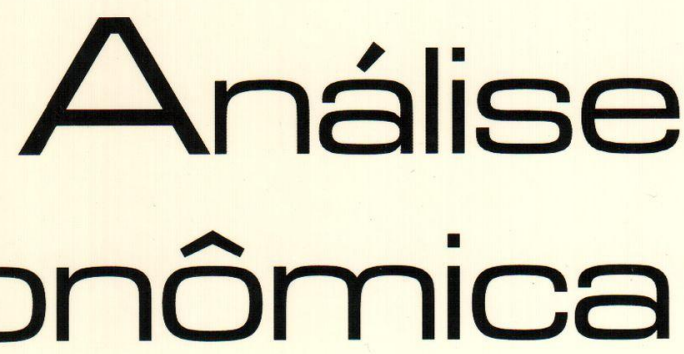


Universidade Federal do Rio Grande do Sul

Reitora: Profa. Wrana Maria Panizzi

Faculdade de Ciencias EConómicas

Diretora: Prof Pedro César Dutra Fonseca

Centro de Estudos e Pesquisas Economicas

Diretor: Prof. Gentil Corazza

Departamento de Ciéncias económicas

Chiefe: Prof. Ricardo Dathein

Curso de Pós. Graduação em Economia

Coordenador: Prof. Eduardo Pontual Ribeiro

Programa de Pós-Graduação em Desenvolvimento Rural

Coordenador: Prof. jalcione Almeida

CONSElHo EDITORIAL:

Carlos G. A. Mielitz Netto (UFRGS), Eduardo A. Maldonado Filho (UFRGS), Eduardo P. Ribeiro (UFRGS), Eleutério F. S. Prado (USP), Eugênio Lagemann (UFRGS), Fernando Cardim de Carvalho (UFRJ), Fernando Ferrari Filho (UFRGS), Fernando de Holanda Barbosa (FGV/RJ), Flávio Vasconcellos Comim (UFRGS), Gentil Corazza (UFRGS), Giácomo Balbinotto Netto (UFRGS), Gustavo Franco (PUC/RJ), Jan A. Kregel (UNCTAD), João Rogério Sanson (UFSC), Joaquim Pinto de Andrade (UnB), Jorge Paulo Araújo (UFRGS), Marcelo S. Portugal (UFRGS), Maria Alice Lahorgue (UFRGS), Paul Davidson (University of Tennessee), Paulo D. Waquil (UFRGS), Pedro C. D. Fonseca (UFRGS), Philip Arestis (Levy Economics Institut of Bard College), Roberto C. de Moraes (UFRGS), Ronald Otto Hillbrecht (UFRGS), Sabino da Silva Porto Jr. (UFRGS), Stefano Florissi (UFRGS) e Werner Baer (University of Illinois at UrbanaChampaign).

COMISSÃO EDITORIAL:

Eduardo Augusto Maldonado Filho, Fernando Ferrari Filho, Gentil Corazza, Marcelo Savino Portugal, Paulo Dabdab Waquil e Roberto Camps Moraes.

EDIroR: Prof. Fernando Ferrari Filho

Editor Adunnio: Prof. Gentil Corazza

SECRETÁrla: Clarissa Roncato Baldim

REVISÁO DE TEXTOS: Vanete Ricacheski

EDITORaÇão Eletrónica: Vanessa Hoffmann de Quadros

Fundador: Prof Antônio Carlos Santos Rosa

Os materiais publicados na revista Análise Econômica são da exclusiva responsabilidade dos autores. É permitida a reprodução total ou parcial dos trabalhos, desde que seja citada a fonte. Aceita-se permuta com revistas congêneres. Aceitam-se, também, livros para divulgação, elaboraçāo de resenhas e recensōes Toda correspondência, material para publicaçāo (vide normas na terceira capa), assinaturas e permutas devem ser dirigidos ao seguinte destinatário:

Análise Econômico

PROF FERNANDO FERRARI FILHO Revisła Análise Econômica - Av. João Pessoa, 52 CEP 90040-000 PORTO ALEGRE - RS, BRASL Telefones: (051) 316-3513 - Fax: (051) 316-3990 E-mail: rae@ufrgs.br

Ano 21, $n^{\circ} 39$, março, 2003 - Porto Alegre

Faculdade de Ciências Econômicas, UFRGS, 2003

Periodicidade semestral, março e setembro.

Tiragem: 500 exemplares

1. Teoria Econômica - Desenvolvimento Regional.

Economia Agrícola - Pesquisa Teórica e Aplicada -

Periódicos. I. Brasil

Faculdade de Ciências Econômicas,

Universidade Federal do Rio Grande do Sul 


\title{
A Política Econômica do Governo Lula: questionando a continuidade e a mudança
}

\author{
Fernando Ferrari Filho** \\ Gentil Corazza**
}

\section{Introdução}

O objetivo deste texto é fazer uma análise crítica da natureza e dos rumos da política econômica do governo Lula, nesses seus primeiros seis meses de atuação. Esta breve análise traduz, antes de tudo, a perplexidade que a mesma provocou em um significativo número de economistas críticos da política econômica anterior, que esperavam ver as propostas de mudança apregoadas pelo novo governo materializarem-se, também, em medidas concretas da política econômica.

Por este motivo, a análise crítica, aqui feita, se apresenta muito mais como um conjunto de questões do que de propostas ou de conclusões. Tais questões podem ser expressas através das seguintes perguntas: Ao justificar que a atual política econômica representa a continuidade da anterior, acrescida de uma dose maior de ortodoxia, devido à gravidade da situação da economia brasileira, o que a equipe econômica quer mesmo dizer? Trata-se apenas de uma questão de tempo ou de ritmo de mudança, mais lento do que o desejado, ou pode-se deduzir da posição do governo que a mudança da política econômica estaria condicionada à melhora da situação da economia brasileira? Ou estaria a equipe econômica sinalizando que não haverá mudança, simplesmente porque não existem políticas econômicas alternativas, uma vez que só existe uma única política econômica, como pregam os manuais ortodoxos? Seria talvez esta a conclusão a ser tirada da afirmação do Ministro da Fazenda de que o governo pretende mudar o modelo econômico, sem mudar ou mantendo a mesma política econômica ortodoxa? Finalmente, como avaliar os primeiros resultados dessa política, positivos, sem dúvida, em relação ao controle da inflação e à melhora da situação cambi-

\footnotetext{
- Artigo entregue à editoria da Revista Análise Econômica em 30 de julho de 2003.

“ Professores titulares da UFRGS e pesquisadores do CNPq.
} 
al, mas profundamente negativos em relação à taxa de juros e à queda do produto e do emprego? Teria ela recriado as condições para a retomada do crescimento econômico ou seriam apenas resultados efêmeros e facilmente reversiveis por qualquer nova mudança dos movimentos do capital financeiro internacional?

\section{O ritmo e a natureza da mudança}

Em seu discurso de posse, realizado no Congresso Nacional, o presidente Lula enfatizou que seu governo iria promover as mudanças necessárias para atacar as questões sociais do País e para retomar o crescimento econômico e, assim, resolver os problemas de desemprego e da distribuição de renda. A mudança, todavia, conforme sinalizou o Presidente, deveria ocorrer ao longo de seu mandato, ou seja, será lenta e gradual. Nesse particular, não constitui nenhuma surpresa o fato da mudança preconizada por Lula vir a ocorrer cautelosamente e por etapas, visto que a expressiva votação que ele recebeu nas eleições de outubro do ano passado transcendeu o âmbito do Partido dos Trabalhadores. Isto é, não deverá haver nenhum sobressalto na implementação da mudança, uma vez que a população que elegeu Lula, então cansada das políticas do ex-presidente Fernando Henrique Cardoso e esperançosa por mudanças substanciais, é constituída por petistas e liberais, sindicalistas e empresários, funcionários públicos e trabalhadores do setor privado e incluídos e excluídos socialmente, entre outros segmentos.

Todavia, passados os primeiros seis meses do governo Lula, parece que as promessas de mudança transformaram-se em retórica, principalmente quando as atenções são voltadas para a política econômica que, até o momento, reproduz as características essenciais da política econômica do governo Fernando Henrique Cardoso. Em outras palavras, a política econômica do ministro Palocci e do presidente do Banco Central, Henrique Meirelles, caminha em direção oposta à onda de esperança que emergiu e "venceu o medo", em 2002, e de mudança preconizada pelo novo Presidente.

\section{Mudar o modelo sem mudar a política macroeconômica?}

Nossa reflexão, nessa linha, deve-se aos fatos que seguem: por um lado, Palocci, em seu discurso de posse, afirmou que pretende "mudar o modelo econômico, sem, contudo, alterar a política 
macroeconômica". Nesse sentido, a proposição do Ministro é que a "mudança" do modelo econômico passe tanto pela reforma tributária e pelas reformas microeconômicas institucionais de cunho liberalizante, tais como a previdenciária e a trabalhista, quanto pelo compromisso de assegurar a vigência da política econômica comumente requerida pelo Fundo Monetário Internacional (FMI).

Já sabemos todos que as medidas de política econômica apregoadas pelo FMI se definem pela obtenção, a qualquer custo, de expressivos superávits fiscais primários, pela liberalização dos mercados financeiros e pela livre flutuação cambial; sem qualquer intervenção do Banco Central. Para ser coerente com essa concepção de "mudança", Palocci e sua equipe econômica resolveram elevar de $3,75 \%$ para $4,25 \%$ do PIB a meta de superávit fiscal primário para os anos de 2003 e 2004, bem como elaboraram um documento no qual atribuem ao desequilíbrio do setor público a principal responsabilidade pela restrição a um processo continuado e sustentável de crescimento da economia brasileira. Além disso, em sintonia com o presidente do Banco Central, o Ministério da Fazenda encaminhou ao Congresso Nacional a proposta de autonomia operacional do Banco Central. Em relação a esta proposta, deve-se notar, em primeiro lugar, que a mesma nunca constou dos programas do Partido dos Trabalhadores e sequer foi proposta ou defendida pelos economistas ligados ao referido Partido. Em segundo lugar, deve-se observar que tal proposição de autonomia operacional do Banco Central sinaliza que a política monetária a ser executada pela referida Instituição será operacionalizada tão-somente para manter a inflação sob controle, negligenciando, assim, a importância de um outro objetivo que, em muitos países, como, por exemplo, os Estados Unidos, também é atribuído ao Banco Central, qual seja, o de procurar compatibilizar o controle da inflação com o crescimento econômico. Neste sentido, em função do conservadorismo do Comitê de Política Monetária (COPOM) do Banco Central, a taxa básica média de juros da economia, nos sete primeiros meses de 2003, ficou ao redor de 26,0\% ao ano ${ }^{1}$. Além do mais, as Atas do COPOM, que explicam as razões das mudanças e/ou o viés das taxas de juros básicas, deixam claro que a política de manutenção de taxas de juros

\footnotetext{
${ }^{1}$ No primeiro bimestre, a Selic foi elevada para $26,5 \%$ ao ano, permanecendo inalterada até junho, quando o COPOM reduziu a taxa básica em $0,5 \%$. Em reunião de julho, a Selic foi reduzida para $24,5 \%$ ao ano.
} 
elevadas é imprescindivel para assegurar o "cumprimento" da meta de inflação.

\section{Os resultados positivos comprovam a eficácia da única política correta?}

A conseqüência imediata do continuísmo da política econômica resultou no restabelecimento da confiança no Brasil por parte do mercado, do FMI e da comunidade financeira internacional - resultando, inclusive, em aporte de capitais de curto prazo, portfólio - na apreciação da taxa de câmbio - cerca de $17,0 \%$, desde o início do ano - na queda vertiginosa do risco-Brasil - atualmente ao redor de 800 pontos, quando há quase um ano o referido risco encontravase próximo a 2.500 pontos - e na valorização dos títulos da dívida externa (C-bonds) no mercado internacional - nas últimas semanas os referidos títulos atingiram, em média, $85,0 \%$ do valor de face.

Apesar dos resultados auspiciosos, acima apresentados, inúmeros críticos da política econômica do governo Lula argumentam que a dupla Palocci-Meirelles utiliza os instrumentos comumente operacionalizados por Malan-Fraga, quais sejam: políticas fiscal e monetária restritivas, que impedem o crescimento e aumentam a taxa de desemprego, como os dados recentes atestam, e não solucionam a vulnerabilidade e a fragilidade externa, essência dos problemas atuais da economia brasileira, inclusive os de natureza inflacionária.

Palocci e Meirelles, por sua vez, convencidos de que parece haver tão-somente uma política econômica correta, seja na transição, seja no longo prazo - por mais que, parafraseando Keynes, "no longo prazo estejamos mortos" - e que tanto as reformas estruturais quanto as políticas sociais, tais como o Programa Fome Zero, são suficientes para propiciar a "mudança" econômica, afirmam que as críticas à política econômica são atribuídas aos "radicais livres" (em um passado recente, eram os "neo-bobos") que não percebem que "propostas alternativas envolvem custos elevados".

Nesse sentido, os articuladores da política econômica insistem que, não havendo turbulências no cenário internacional, a restrição externa da economia brasileira deixa de se constituir em um problema para o crescimento econômico e, portanto, as atençōes voltam-se para a questão fiscal, principal elemento de constrangimento do referido crescimento. 


\section{Será correto o diagnóstico da equipe econômica?}

Em outras palavras, terá a economia brasileira superado sua vulnerabilidade e fragilidade externa e, por conseguinte, o bottleneck é o desequilibrio fiscal?

Em nosso ponto de vista, por mais que a questão do desequilíbrio fiscal mereça a devida atenção da política econômica, a economia brasileira, a despeito da melhora substancial dos indicadores externos nos primeiros meses de 2003, está longe de superar o quadro de vulnerabilidade e de fragilidade externa. Tal conclusāo decorre das seguintes observações:

(i) ao longo dos próximos anos a necessidade de financiamento externo, caracterizada pelo déficit do balanço de pagamentos em transações correntes e pela amortização, está estimada entre US\$ 25,0 e 30,0 bilhões $^{2}$;

(ii) a abertura comercial da economia brasileira nos anos 1990 tornou nossa economia muito dependente de insumos importados e, como conseqüência, qualquer expansão mais dinâmica da produção industrial pressiona as importações;

(iii) o perfil de ingresso de capitais sob a ótica de investimento de risco é nitidamente direcionado para os setores nontradables, o que compromete, no futuro, a balança de serviços, quando da remessa de royalties, lucros e dividendos, bem como, devido ao desaquecimento da economia mundial, as expectativas de ingresso de investimento de risco não são das mais otimistas, comparativamente a períodos passados - um exemplo disto, é que, grosso modo, os capitais que atualmente têm ingressado na economia brasileira são predominantemente de portfólio;

(iv) o desaquecimento das economias norte-americana e européia, a estagnação da economia japonesa e a lenta "recuperação" da Argentina, principais parceiros comerciais do Brasil, podem arrefecer o ritmo de crescimento das exportaçōes brasileiras.

${ }^{2}$ Nesse ponto, é pouco provável que, em um contexto de desaquecimento da economia mundial e de redução da liquidez internacional para países emergentes, a economia brasileira continuará absorvendo um volume de "poupança externa" anual suficiente para financiar seu balanço de pagamentos, conforme vinha acontecendo no passado. É importante mencionar que, entre 2000 e 2002, o pagamento de juros e de amortização foi, em média, cerca de US\$ 40,0 bilhões ao ano. 


\section{Os novos rumos da política econômica}

Em suma, ao contrário do discurso sincronizado da equipe econômica, a economia brasileira está longe de resolver seus problemas de vulnerabilidade e fragilidade externas e, portanto, de remover as sérias restrições à retomada de um processo de crescimento econômico sustentável.

Por esse motivo, entendemos que tentar reverter a restriçāo externa deva ser a estratégia da política econômica, uma vez que ela é condição fundamental para estimular a atividade econômica, sem comprometer a estabilização dos preços. Para tanto, os novos rumos da política econômica deveriam contemplar os seguintes pontos:

(i) adoção de políticas tributárias e financeiras de estímulo às exportaçōes - por exemplo, desonerando as exportações e abrindo linhas de crédito para as mesmas, via Banco Nacional de Desenvolvimento Econômico e Social (BNDES);

(ii) administração da taxa de câmbio pelo Banco Central do Brasil de tal forma que as ações especulativas possam ser coibidas ou, em outras palavras, que o regime cambial seja operado conforme o sistema crawling peg3;

(iii) estruturação pelo Governo e setor privado de uma política industrial de maneira que a inserção da economia brasileira no cenário internacional ocorra de forma a absorver as revoluções tecnológica e estrutural em curso - imprescindíveis para tornar nossos produtos competitivos no mercado mundial - e a atrair participação de capital estrangeiro em investimentos produtivos que possam gerar valor agregado, visando à exportação - isto é, tradables;

(iv) revisão da política comercial, tendo como referência os acordos da Organização Mundial do Comércio que possibilitam tratamento especial para os países em desenvolvimento, no sentido de adoção de tarifas seletivas que privilegiem as importações de bens de capital e penalizem as importações de bens de consumo;

(v) priorização das relações comerciais e financeiras com os parceiros do Mercosul, visando, assim, aumentar o poder de barga-

\footnotetext{
${ }^{3}$ A idéia consiste em estabelecer uma margem de flutuação ex ante da taxa de câmbio de maneira que a autoridade monetária possa intervir no mercado de divisas sempre que a taxa de câmbio se aproximar dos valores extremos, superior e inferior, da margem de flutuação previamente estabelecida. Dessa maneira, a determinação prévia da flutuação da taxa de câmbio pode influir nas expectativas dos agentes econômicos.
} 
nha do Brasil e dos demais países do Mercosul no processo de integração do Acordo de Livre Comércio das Américas (ALCA);

(vi) criação pelo Banco Central de mecanismos antiespeculativos eficientes para controlar (ou regular) os movimentos de capitais, de forma a evitar a ocorrência de crises monetário-cambiais via contágio dos mercados financeiros.

Em conclusão, a adoção deste conjunto de medidas, aliadas a outras possíveis, deve contribuir para remover as restrições e diminuir a vulnerabilidade e fragilidade externas da economia brasileira e restaurar progressivamente a autonomia da política econômica, de forma a torná-la mais condizente com um novo modelo de desenvolvimento econômico e social para o País e, assim, concretizar as prometidas e necessária mudanças, que todos almejamos. 